\title{
Cardiorespiratory fitness and telomere length: a systematic review
}

Adilson Marques, Élvio Rubio Gouveira, Miguel Peralta, João Martins, Joed Venturini, Duarte Henriques-Neto \& Hugo Sarmento

To cite this article: Adilson Marques, Élvio Rubio Gouveira, Miguel Peralta, João Martins, Joed Venturini, Duarte Henriques-Neto \& Hugo Sarmento (2020) Cardiorespiratory fitness and telomere length: a systematic review, Journal of Sports Sciences, 38:14, 1690-1697, DOI: 10.1080/02640414.2020.1754739

To link to this article: https://doi.org/10.1080/02640414.2020.1754739

曲 Published online: 14 Apr 2020.

Submit your article to this journal $\sqsubset$

山ll Article views: 333

Q View related articles ¿

View Crossmark data $\sqsubset$

Citing articles: 5 View citing articles ए 


\title{
Cardiorespiratory fitness and telomere length: a systematic review
}

\author{
Adilson Marques $\mathbb{D D}^{\mathrm{a}, \mathrm{b}}$, Élvio Rubio Gouveirac, ${ }^{\mathrm{c}}$, Miguel Peralta $\mathbb{D}^{\mathrm{a}, \mathrm{b}}$, João Martins $\mathbb{D}^{\mathrm{b}, \mathrm{e}}$, Joed Venturinif, \\ Duarte Henriques-Neto (iD ${ }^{a}$ and Hugo Sarmento (iD ${ }^{g}$
}

${ }^{a}$ Centro Interdisciplinar do Estudo da Performance Humana, Faculdade de Motricidade Humana, Universidade de Lisboa, Lisboa, Portugal; blnstituto de Saúde Ambiental, Faculdade de Medicina, Universidade de Lisboa, Lisboa, Portugal; 'Departamento de Educação Física e Desporto, Universidade da Madeira, Funchal, Portugal; ${ }^{d}$ Interactive Technologies Institute, LARSyS, Funchal, Portugal; eLaboratório de Pedagogia, Faculdade de Motricidade Humana e UIDEF, Instituto de Educação, Universidade de Lisboa, Lisboa, Portugal; 'NNOVA Medical School, Universidade NOVA de Lisboa, Lisboa, Portugal; ${ }^{9}$ Research Unit for Sport and Physical Activity, Faculty of Sport Sciences and Physical Education, University of Coimbra, Coimbra, Portugal

\begin{abstract}
This study aimed to systematically review the association between cardiorespiratory fitness and telomere length (TL). Studies were identified from searches in Cochrane Central, PubMed, Scopus, Sportdiscus, and Web of Science databases through July 2019. Eligibility criteria included: cross-sectional, prospective, and experimental study design; outcomes included TL; results expressed the relationship between cardiorespiratory fitness and TL; studies published in English, Portuguese, or Spanish. A total of 20 articles met the inclusion criteria. Sixteen studies (80\%) reported a significant relationship between cardiorespiratory fitness, or training load, and TL. Better cardiorespiratory fitness or a large cardiorespiratory training load are associated with an increase in TL. Although, TL was related to regular moderate-to-vigorous aerobic exercise and cardiorespiratory fitness in older healthy humans, it was not related to cardiorespiratory fitness among young subjects. There seems to be a positive and significant relationship between cardiorespiratory fitness and TL, mainly among middle age and older people, which emphasizes the importance of cardiorespiratory fitness for healthy ageing. Therefore, endurance exercise and better cardiorespiratory fitness may regulate the TL in middle age and older adults, slowing the cellular ageing process.
\end{abstract}

\section{ARTICLE HISTORY}

Accepted 1 April 2020

\section{KEYWORDS}

Aerobic fitness; DNA; exercise; endurance; physical activity; running

\section{Introduction}

Telomeres are the region at the end of each strand of deoxyribonucleic acid (DNA), functioning as caps, which maintain genome stability. Telomeres are essential to protect vital information in the DNA and prevent undesired chromosomal rearrangements (Eisenberg, 2011; De Lange, 2009). Telomeres play a vital role in health, as their length is associated with several chronic diseases, such as cardiovascular diseases (Fyhrquist \& Saijonmaa, 2012), diabetes (Zhao et al., 2013), psychological disorders (Zhang et al., 2014), and cancer (Ma et al., 2011).

Human cells are constantly copying themselves, and each time a cell copies itself telomeres shorten (Eisenberg, 2011). Therefore, as people age, telomeres are naturally shortened. Telomere length (TL) is associated with cellular ageing and can represent biologic age (Arsenis et al., 2017). With the shortened telomeres, DNA strands eventually become damaged and cell senescence or apoptosis is induced (Eisenberg, 2011; Oeseburg et al., 2010). Even though telomere shortening is a natural ageing process, it can be accelerated by other factors that promote oxidative stress and inflammation (Houben et al., 2008; Wolkowitz et al., 2011). Sedentary behaviour is known to increase the body's oxidative stress. Regular physical activity seems to improve antioxidant activity (Bjork et al., 2012; Gomes et al., 2012) and inflammatory balance (Kasapis \& Thompson, 2005; Nimmo et al., 2013).

More substantial than physical activity, is its effects on the organism. Better cardiorespiratory fitness is an outcome of increased physical activity, which is independently associated with health (Imboden et al., 2018; Lin et al., 2015). Additionally, cardiorespiratory fitness is associated with oxidative stress biomarkers (Shammas, 2011). As oxidative stress can accelerate telomere attrition, and physical activity has been inconstantly related to $T L$, it is meaningful to investigate the relationship between cardiorespiratory fitness and TL. Some studies have pointed towards a positive relationship (Krauss et al., 2011; LaRocca et al., 2010; Mason et al., 2012), however this evidence was never synthesized or summarized in a review. Thus, the aim of this study was to systematically review the association between cardiorespiratory fitness and TL. Although a previous study has systematically review the relationship between $T L$ and physical activity, concluding that it remains an open question (Mundstock et al., 2015), this is the first study to systematically review the relationship between cardiorespiratory fitness and TL.

\section{Methods}

This systematic review was performed in accordance with the Preferred Reporting Items for Systematic Reviews and MetaAnalysis (PRISMA) guidelines (Moher et al., 2009), and the association of Physical Activity and Academic Performance Protocol for Systematic Reviews and Meta-Analysis (Alvarez-Bueno et al., 2016). 


\section{Search strategy}

During August 2019, studies were identified by searching, in electronic databases, for peer-reviewed articles published up to July 2019. The search was applied to Cochrane Central, PubMed, Scopus, Sportdiscus, and Web of Science. Additionally, the reference lists of included studies were searched. Articles that assessed the relationship between cardiorespiratory fitness and TL were included in this review. The search was performed using the following combination of terms: fitness OR endurance OR cardiorespiratory OR aerobic AND telomere. Search terms were defined among the research team and were used in each database to identify potential articles with abstracts for review. Two reviewers worked independently and screened titles and abstracts to identify studies that met the inclusion criteria. Duplicate entries were removed. Relevant articles were retrieved for a full read. The same two authors reviewed the full text of potential studies, and decisions to include or exclude studies in the review were made by consensus. Disagreements were solved by consensus and, when necessary, a third reviewer served as a judge.

\section{Inclusion criteria}

Source articles published up to July 2019, in peer-reviewed journals, were eligible for inclusion if they presented the relationship between cardiorespiratory fitness and TL. Eligibility criteria included the following: (1) cross-sectional, prospective, and experimental study design (study design criterion); (2) outcomes included TL (outcome measure criterion); (3) cardiorespiratory fitness and TL (relationship criterion); (4) young, adults and older adults (participants criterion); (5) articles published in English, Portuguese, or Spanish (language criterion); (6) articles were excluded if they did not meet inclusion criteria or did not include findings related to the inclusion criteria (exclusion criteria).

\section{Data extraction and harmonization}

A data extraction form was developed, based on PRISMA statement (Moher et al., 2009). The following information was extracted from each article: authors' name and year of publication, study design, sample characteristics (number of participants, sex, age), country, tissue or fluid and method of TL evaluation, methods of cardiorespiratory fitness evaluation or training load, study quality, and main results. The extraction was carried out by one author, and coding was verified by other two authors.

\section{Study quality and risk of bias}

The methodological quality of the studies was assessed by two independent researchers using the Physiotherapy Evidence Database (PEDro) scale. Agreement between reviewers was assessed using $\mathrm{k}$ statistics $(\mathrm{k}=0.96)$ for full-text screening and rating of relevance and risk of bias. In the disagreement about the risk of bias, a third reviewer checked the data and made the final decision. A data extraction form from Cochrane Consumers and Communication Review Group's data extraction template (Group CCCR, 2016) was modified to this review's study inclusion requirements and tested on ten randomly selected studies (pilot test). The quality of the included studies was assessed with a total score ranging from zero to 11 .

\section{Synthesis of results}

The review analysed the relationship between cardiorespiratory fitness and TL. Significant heterogeneity existed within study for several study parameters. These parameters included: the participant characteristics, tissue or fluid used to analyse telomeres, method of TL evaluation, and methods of cardiorespiratory fitness evaluation. The details for each study, including design, measures, participant characteristics and sample size, and study quality and results are presented in a consistent manner.

\section{Results}

\section{Search results}

Ninety-seven articles were yielded from five databases. Three additional studies, that were found as references in the retrieved articles, were also included. After excluding 55 duplicated articles, 42 were selected for abstract reading. Of those, nine articles were excluded at the abstract level. The remaining 33 articles were read in full. Among these, three were excluded because they utilized animal samples, four were not empirical studies, and six did not report the association between cardiorespiratory fitness and TL. Therefore, 20 articles were included in the systematic review (Figure 1).

Table 1 summarizes the study's characteristics. The review of 20 studies accounts for 9705 subjects, and research was predominantly from the United States of America (7 studies), and Europe (6 studies). The rest of the studies were from Australia (3 studies), Brazil (2 studies), South Africa (1 study), and South Korea (1 study). Among the studies, 13 were cross-sectional, observational and comparative studies, four were randomized control trials (RCT), two were cross-sectional observational, and one was cross-sectional and prospective. The most frequent method to assess TL was polymerase chain reaction (PCR) (12/ $20)$, followed by Southern blot (3/20), flow-fluorescence in situ hybridization (FISH) (2/20), terminal restriction fragment (TRF) (1/ 20), fluorescein isothiocyanate (FITC) (1/20), and repeat copy number/single-gene copy number (1/20). The most frequent method used to evaluate cardiorespiratory fitness or training load was through a maximal graded treadmill or cycle ergometer test to estimate VO2 max consumption. However, some studies did not assess objectively the cardiorespiratory fitness level because the subjects were experienced endurance athletes (e.g. ultramarathon runners, runners who run $\geq 40 \mathrm{~km} /$ week).

\section{Main findings}

Sixteen studies (80\%) reported a significant relationship between cardiorespiratory fitness, or training load, and TL (Borghini et al., 2015; Denham et al., 2013, 2016; Diman et al., 2016; Edwards \& Loprinzi, 2017; Krauss et al., 2011; LaRocca et al., 2010; Mason et al., 2012; Østhus et al., 2012; Puterman et al., 2018; Silva et al., 2016; Soares-Miranda et al., 2015; Sousa et al., 2019; C Werner et al., 2009; CM Werner et al., 2019; Williams et 


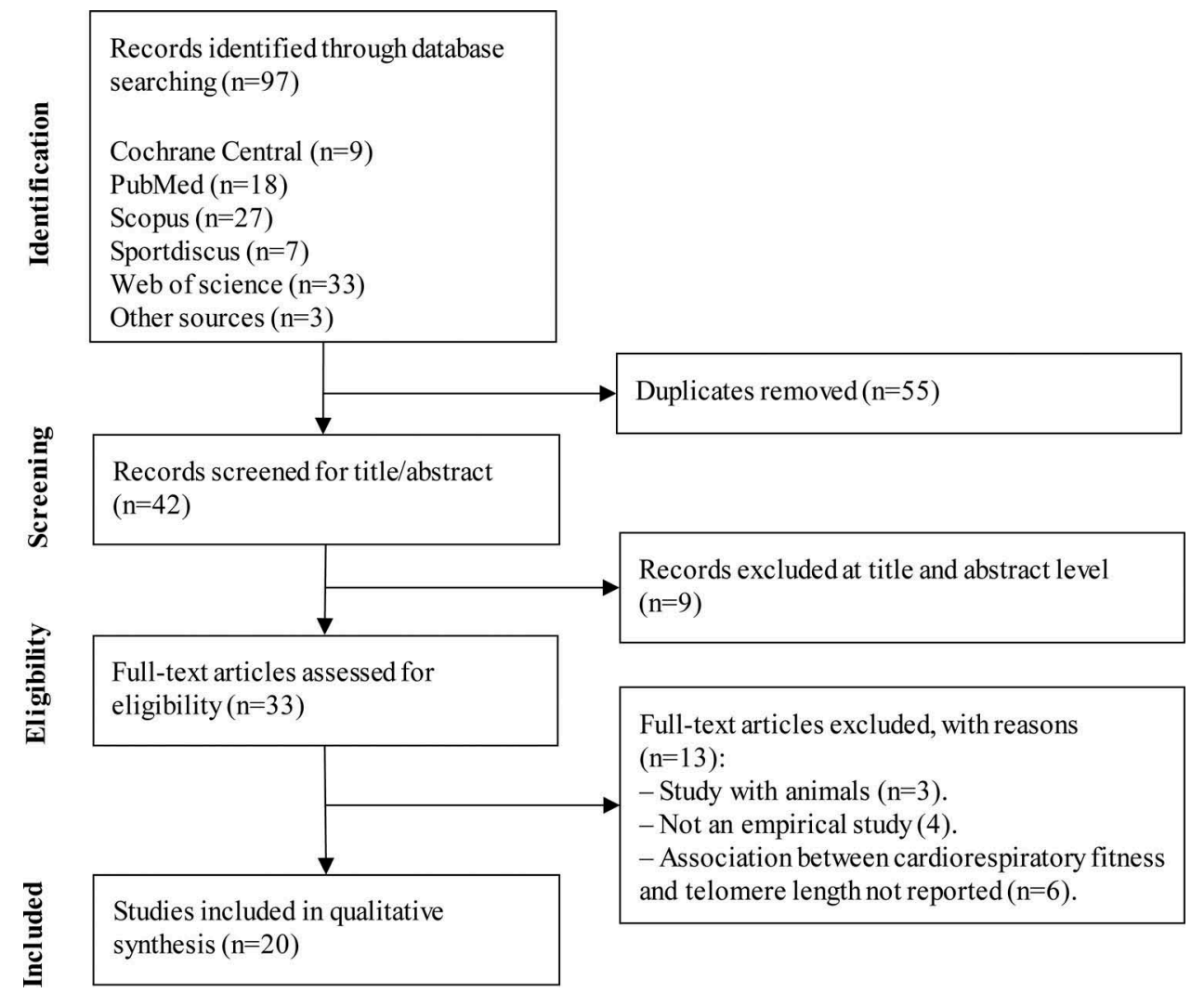

Figure 1. Flow diagram of study selection.

al., 2017). Better cardiorespiratory fitness or a large cardiorespiratory training load are associated with an increase in TL. Among those studies, it was observed that TL is related to regular moderate-to-vigorous aerobic exercise and cardiorespiratory fitness in older healthy humans, but it is not related to cardiorespiratory fitness among young subjects (LaRocca et al., 2010; Østhus et al., 2012). In one RCT study (Mason et al., 2012), at baseline, TL was inversely associated with age and positively associated with VO2max. However, compared to controls, there were no significant changes in TL over 12months in intervention groups.

Three cross-sectional comparative studies (Denham, 2017; Mathur et al., 2013; Rae et al., 2010), and one RCT study (Shin et al., 2008) did not find any statistically significant association between cardiorespiratory fitness and TL. Yet, one of those studies (Rae et al., 2010) showed that the telomere terminal restriction fragment length of the athletes who used to run $\geq 40 \mathrm{~km} /$ week was negatively correlated to their years of distance running and the time spent training.

\section{Discussion}

The current review summarizes studies published up to July 2019 that meet the defined criteria. Twenty studies that used different study designs were systematically reviewed to address the relationship between cardiorespiratory fitness and TL. In general, it was found that TL was better preserved in endurance-trained people and among those with better cardiorespiratory fitness. However, in four studies the TL was not associated with endurance exercise and fitness parameters such as VO2max. Thus, the evidence suggests that cardiorespiratory fitness is an important outcome of the physical activity that might be important to preserve $\mathrm{TL}$, but it is still an open question that needs more research in order to be clarified.

In most studies, middle age or older habitual runners, and people with better cardiorespiratory fitness, had longer telomeres than less-trained individuals (LaRocca et al., 2010; Sousa et al., 2019). In one study with young adults and middle age adults, it was observed that middle age runners had longer telomeres than age-matched controls (Sousa et al., 2019). However, the untrained middle age group had shorter telomeres than young untrained, and there was not differences between young untrained and middle age runners. It seems that cardiorespiratory fitness is more important for TL preservation among middle age and older adults than among young adults (LaRocca et al., 2010). In fact, TL and its attrition over time is variable among people, but it is relatively stable from childhood to adulthood (Oeseburg et al., 2010). This can explain the inconsistent results observed among young adults (LaRocca et al., 2010; Østhus et al., 2012; Sousa et al., 2019). Perhaps, TL in young adults have not yet experience attrition, but will be affected by the reduction of telomerase activity associated with sedentary lifestyle (Arsenis et al., 2017). The positive association of TL and active lifestyle indicated that it is a biomarker of healthy ageing (Njajou et al., 2009). Nonetheless, even among young adults some studies have shown that cardiorespiratory fitness can also be important in preserving TL (Borghini et al., 2015; Denham et al., 2013, 2016; Edwards \& Loprinzi, 2017; C Werner et al., 2009; Williams et al., 2017).

Although cardiorespiratory fitness seems to be important to resist telomere attrition and attenuate biological ageing, it has 


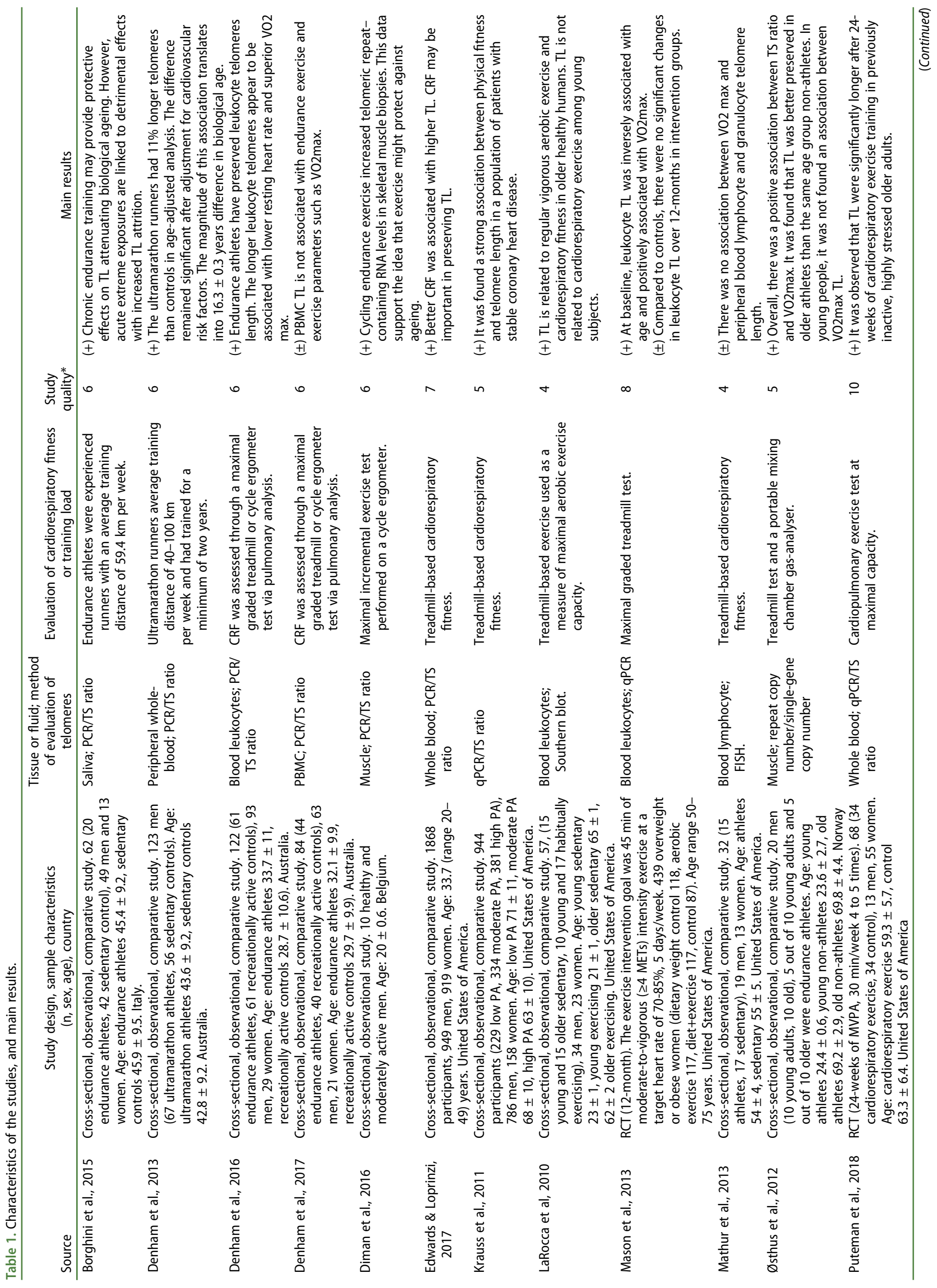




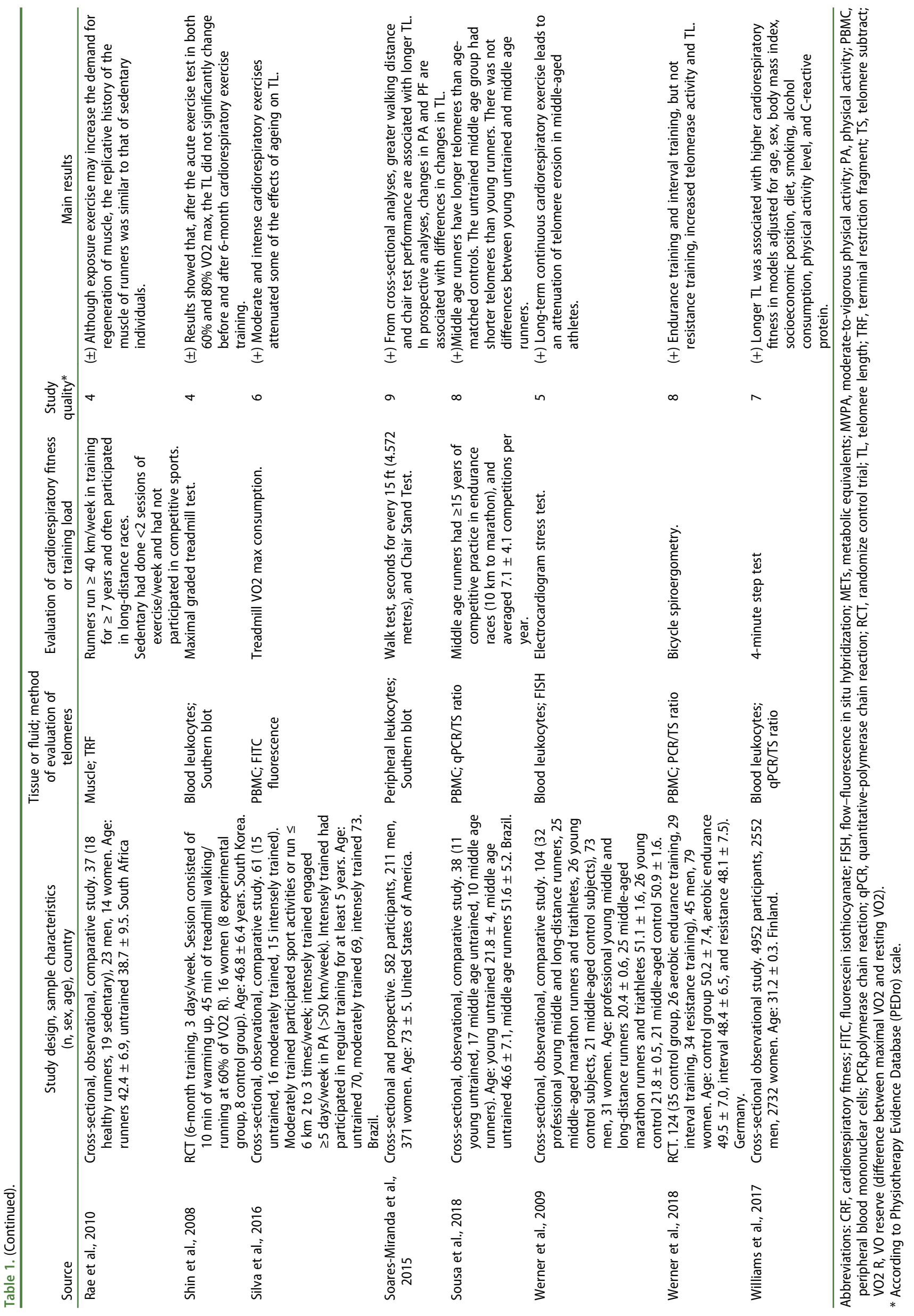


been reported that there is an inverse $U$ curve associated to an increase in physical activity (Ludlow et al., 2008) and cardiorespiratory exercise (Borghini et al., 2015; Østhus et al., 2012). Time spent sedentary and high intensity activities are associated with shorter telomeres, while on the other hand, moderate and vigorous activities are associated with longer telomeres (Borghini et al., 2015; Ludlow et al., 2008; Østhus et al., 2012; Silva et al., 2016). Acute exposure to extreme activity could shorten telomeres because of excessive reactive oxygen species production (Saretzki \& Von Zglinicki, 2002). Extreme exercise is responsible for oxidative stress (Bjork et al., 2012) which is known to induce persistent telomeric DNA damage (Coluzzi et al., 2014). Telomere transcription is activated by NRF1 antioxidant factor. Thus, it can be speculated that telomeric repeat-containing RNA up-regulation might be part of the antioxidant reaction that muscles set up to counteract exercise-induced reactive oxygen species (Powers et al., 1999).

The potential molecular mechanisms underlying the relationship between cardiorespiratory fitness and TL are unclear. However, there are several potential explanations (Arsenis et al., 2017). It has been proposed that regular physical activity and increasing cardiorespiratory fitness lead to an improvement of REDOX balance and the hindering of inflammatory activity (Gomes et al., 2012). The improvement in the antioxidant response increases DNA-repairing enzymes (Radak et al., 2003), and naturally decreases the production of reactive oxygen species (Bjork et al., 2012). Furthermore, acute exercise sessions temporarily increase the inflammatory process (Liburt et al., 2010). The effect of the inflammatory process is compensated by regular exercise practice that increases an anti-inflammatory response (Kasapis \& Thompson, 2005). The antioxidant response to cardiorespiratory exercise, and the anti-inflammatory reaction, leads to the hormones processed in response to low and high doses of stressors (Kendig et al., 2010; Ristow \& Zarse, 2010). These potential mechanisms are in accordance with the observed $U$ curve found in some studies (Borghini et al., 2015; Ludlow et al., 2008). Furthermore, cardiorespiratory exercise is positively related to: activation of telomerase (Kadi \& Ponsot, 2010), improved body composition, and a decrease in low-density lipoproteins (Sirabella et al., 2013). All of which are important to preserve TL through the modulation of telomerase dynamics (Kadi \& Ponsot, 2010; Ludlow et al., 2008).

Some study limitations have to be addressed. First, the differences in sample size, tissue sources, methods of evaluation of telomeres and cardiorespiratory fitness may have weakened the evidence. Second, the wide variety among study methodologies precludes the possibility of performing a meta-analysis. Third, in spite of the fact that studies were assessed according to their methodological quality, they were not weighted or ranked. As a result, findings from studies with a weaker methodological quality and smaller sample size were given no less importance than findings from others with strong research designs and larger sample sizes.

\section{Conclusion}

This review suggests a positive and significant relationship between cardiorespiratory fitness and $\mathrm{TL}$, mainly among middle age and older people. The positive association between cardiorespiratory fitness and TL emphasizes the importance of cardiorespiratory fitness for healthy ageing. Endurance exercise and better cardiorespiratory fitness may regulate the TL in middle age and older adults, slowing the cellular ageing process. Large-scale longitudinal studies are necessary to better assess the role of long-term cardiorespiratory fitness on $\mathrm{TL}$ with ageing.

\section{Disclosure statement}

The authors report no conflict of interest.

\section{ORCID}

Adilson Marques (iD http://orcid.org/0000-0001-9850-7771 Miguel Peralta (iD http://orcid.org/0000-0001-6072-6012 João Martins (iD http://orcid.org/0000-0002-2540-6678 Duarte Henriques-Neto (iD) http://orcid.org/0000-0003-3780-6545 Hugo Sarmento (iD) http://orcid.org/0000-0001-8681-0642

\section{References}

Alvarez-Bueno, C., Pesce, C., Cavero-Redondo, I., Sanchez-Lopez, M., PardoGuijarro, M. J., \& Martinez-Vizcaino, V. (2016). Association of physical activity with cognition, metacognition and academic performance in children and adolescents: A protocol for systematic review and metaanalysis. BMJ Open, 6(6), e011065. https://doi.org/10.1136/bmjopen2016-011065

Arsenis, N. C., You, T., Ogawa, E. F., Tinsley, G. M., \& Zuo, L. (2017). Physical activity and telomere length: Impact of aging and potential mechanisms of action. Oncotarget, 8(27), 45008-45019. https://doi.org/10.18632/ oncotarget.16726

Bjork, L., Jenkins, N. T., Witkowski, S., \& Hagberg, J. M. (2012). Nitro-oxidative stress biomarkers in active and inactive men. International Journal of Sports Medicine, 33(4), 279-284. https://doi.org/10.1055/s-0032-1301891

Borghini, A., Giardini, G., Tonacci, A., Mastorci, F., Mercuri, A., Sposta, S. M., Moretti, S., Andreassi, M. G., \& Pratali, L. (2015). Chronic and acute effects of endurance training on telomere length. Mutagenesis, 30(5), 711-716. https://doi.org/10.1093/mutage/gev038

Coluzzi, E., Colamartino, M., Cozzi, R., Leone, S., Meneghini, C., O'Callaghan, N., \& Sgura, A. (2014). Oxidative stress induces persistent telomeric DNA damage responsible for nuclear morphology change in mammalian cells. PloS One, 9 (10), e110963. https://doi.org/10.1371/journal.pone.0110963

De Lange, T. (2009). How telomeres solve the end-protection problem. Science, 326(5955), 948-952. https://doi.org/10.1126/science.1170633

Denham, J. (2017). Lack of association between PBMC telomere length and endurance exercise. Journal of Applied Biomedicine, 15(1), 9-13. https:// doi.org/10.1016/j.jab.2016.09.004

Denham, J., Nelson, C. P., O’Brien, B. J., Nankervis, S. A., Denniff, M., Harvey, J. T., Marques, F. Z., Codd, V., Zukowska-Szczechowska, E., Samani, N. J., Tomaszewski, M., \& Charchar, F. J. (2013). Longer leukocyte telomeres are associated with ultra-endurance exercise independent of cardiovascular risk factors. PloS One, 8(7), 7. https://doi.org/10.1371/journal.pone. 0069377

Denham, J., O'Brien, B. J., Prestes, P. R., Brown, N. J., \& Charchar, F. J. (2016). Increased expression of telomere-regulating genes in endurance athletes with long leukocyte telomeres. Journal of Applied Physiology, 120 (2), 148-158. https://doi.org/10.1152/japplphysiol.00587.2015

Diman, A., Boros, J., Poulain, F., Rodriguez, J., Purnelle, M., Episkopou, H., Bertrand, L., Francaux, M., Deldicque, L., \& Decottignies, A. (2016). Nuclear respiratory factor 1 and endurance exercise promote human telomere transcription. Science Advances, 2(7), 7. https://doi.org/10. 1126/sciadv.1600031

Edwards, M. K., \& Loprinzi, P. D. (2017). Sedentary behavior, physical activity and cardiorespiratory fitness on leukocyte telomere length. Health Promotion Perspectives, 7(1), 22-27. https://doi.org/10.15171/hpp.2017.05 
Eisenberg, D. T. (2011). An evolutionary review of human telomere biology: The thrifty telomere hypothesis and notes on potential adaptive paternal effects. American Journal of Human Biology, 23(2), 149-167. https:// doi.org/10.1002/ajhb.21127

Fyhrquist, F., \& Saijonmaa, O. (2012). Telomere length and cardiovascular aging. Annals of Medicine, 44(Suppl 1), S138-142. https://doi.org/10. 3109/07853890.2012.660497

Gomes, E. C., Silva, A. N., \& Oliveira, M. R. (2012). Oxidants, antioxidants, and the beneficial roles of exercise-induced production of reactive species. Oxidative Medicine and Cellular Longevity, 2012, 756132. https://doi.org/ $10.1155 / 2012 / 756132$

Group CCCR. Data Extraction Template for Included Studies 2016. Australia: La Trobe University.

Houben, J. M., Moonen, H. J., van Schooten, F. J., \& Hageman, G. J. (2008). Telomere length assessment: Biomarker of chronic oxidative stress? Free Radical Biology and Medicine, 44(3), 235-246. https://doi.org/10.1016/j. freeradbiomed.2007.10.001

Imboden, M. T., Harber, M. P., Whaley, M. H., Finch, W. H., Bishop, D. L., \& Kaminsky, L. A. (2018). Cardiorespiratory fitness and mortality in healthy men and women. Journal of the American College of Cardiology, 72(19), 2283-2292. https://doi.org/10.1016/j.jacc.2018.08.2166

Kadi, F., \& Ponsot, E. (2010). The biology of satellite cells and telomeres in human skeletal muscle: Effects of aging and physical activity. Scandinavian Journal of Medicine \& Science in Sports, 20(1), 39-48. https://doi.org/10.1111/j.1600-0838.2009.00966.x

Kasapis, C., \& Thompson, P. D. (2005). The effects of physical activity on serum C-reactive protein and inflammatory markers: A systematic review. Journal of the American College of Cardiology, 45(10), 15631569. https://doi.org/10.1016/j.jacc.2004.12.077

Kendig, E. L., Le, H. H., \& Belcher, S. M. (2010). Defining hormesis: Evaluation of a complex concentration response phenomenon. International Journal of Toxicology, 29(3), 235-246. https://doi.org/10.1177/1091581810363012

Krauss, J., Farzaneh-Far, R., Puterman, E., Na, B., Lin, J., Epel, E., Blackburn, E., \& Whooley, M. A. (2011). Physical fitness and telomere length in patients with coronary heart disease: Findings from the Heart and Soul Study. PloS One, 6(11), e26983. https://doi.org/10.1371/journal.pone.0026983

LaRocca, T. J., Seals, D. R., \& Pierce, G. L. (2010). Leukocyte telomere length is preserved with aging in endurance exercise-trained adults and related to maximal aerobic capacity. Mechanisms of Ageing and Development, 131(2), 165-167. https://doi.org/10.1016/j.mad.2009.12.009

Liburt, N. R., Adams, A. A., Betancourt, A., Horohov, D. W., \& McKeever, K. H. (2010). Exercise-induced increases in inflammatory cytokines in muscle and blood of horses. Equine Veterinary Journal, 42(38), 280-288. https:// doi.org/10.1111/j.2042-3306.2010.00275.x

Lin, X., Zhang, X., Guo, J., Roberts, C. K., McKenzie, S., Wu, W.-C., Liu, S., \& Song, Y. (2015). Effects of exercise training on cardiorespiratory fitness and biomarkers of cardiometabolic health: A systematic review and metaanalysis of randomized controlled trials. Journal of the American Heart Association, 4(7), e002014. https://doi.org/10.1161/JAHA.115.002014

Ludlow, A. T., Zimmerman, J. B., Witkowski, S., Hearn, J. W., Hatfield, B. D., \& Roth, S. M. (2008). Relationship between physical activity level, telomere length, and telomerase activity. Medicine \& Science in Sports \& Exercise, 40 (10), 1764-1771. https://doi.org/10.1249/MSS.0b013e31817c92aa

Ma, H., Zhou, Z., Wei, S., Liu, Z., Pooley, K. A., Dunning, A. M., Svenson, U., Roos, G., Hosgood, H. D., Shen, M., \& Wei, Q. (2011). Shortened telomere length is associated with increased risk of cancer: A meta-analysis. PloS One, 6(6), e20466. https://doi.org/10.1371/journal.pone.0020466

Mason, C., Risques, R. A., Xiao, L., Duggan, C. R., Imayama, I., Campbell, K. L., Kong, A., Foster-Schubert, K. E., Wang, C.-Y., Alfano, C. M., Blackburn, G. L., Rabinovitch, P. S., \& McTiernan, A. (2012). Independent and combined effects of dietary weight loss and aerobic exercise on leukocyte telomere length in overweight and obese postmenopausal women. Cancer Prevention Research (Philadelphia, Pa.)., 5(11 SUPPL), 1. https://doi.org/ 10.1158/1940-6207.PREV-12-A01

Mathur, S., Ardestani, A., Parker, B., Cappizzi, J., Polk, D., \& Thompson, P. D. (2013). Telomere length and cardiorespiratory fitness in marathon runners. Journal of Investigative Medicine, 61(3), 613-615. https://doi.org/10. 2310/JIM.0b013e3182814cc2

Moher, D., Liberati, A., Tetzlaff, J., Altman, D. G., \& Group, P. (2009). Preferred reporting items for systematic reviews and meta-analyses: The PRISMA statement. Annals of Internal Medicine, 151(4), 264-269, W264. https:// doi.org/10.7326/0003-4819-151-4-200908180-00135

Mundstock, E., Zatti, H., Louzada, F. M., Oliveira, S. G., Guma, F. T. C. R., Paris, M. M., Rueda, A. B., Machado, D. G., Stein, R. T., Jones, M. H., Sarria, E. E., Barbé-Tuana, F. M., \& Mattiello, R. (2015). Effects of physical activity in telomere length: Systematic review and meta-analysis. Ageing Research Reviews, 22, 72-80. https://doi.org/10.1016/j.arr.2015.02.004

Nimmo, M. A., Leggate, M., Viana, J. L., \& King, J. A. (2013). The effect of physical activity on mediators of inflammation. Diabetes, Obesity \& Metabolism, 15(Suppl 3), 51-60. https://doi.org/10.1111/dom.12156

Njajou, O. T., Hsueh, W. C., Blackburn, E. H., Newman, A. B., Wu, S.-H., Li, R., Simonsick, E. M., Harris, T. M., Cummings, S. R., \& Cawthon, R. M. (2009). Association between telomere length, specific causes of death, and years of healthy life in health, aging, and body composition, a population-based cohort study. The Journals of Gerontology: Series A, 64(8), 860864. https://doi.org/10.1093/gerona/glp061

Oeseburg, H., de Boer, R. A., van Gilst, W. H., \& Van der Harst P. (2010). Telomere biology in healthy aging and disease. Pflugers Archiv : European Journal of Physiology, 459(2), 259-268. https://doi.org/10. 1007/s00424-009-0728-1

Østhus, I. B., Sgura, A., Berardinelli, F., Alsnes, I. V., Brønstad, E., Rehn, T., Støbakk, P. K., Hatle, H., Wisløff, U., \& Nauman, J. (2012). Telomere length and long-term endurance exercise: Does exercise training affect biological age? A pilot study. PloS One, 7(12), e52769. https://doi.org/10.1371/ journal.pone.0052769

Powers, S. K., Ji, L. L., \& Leeuwenburgh, C. (1999). Exercise training-induced alterations in skeletal muscle antioxidant capacity: A brief review. Medicine \& Science in Sports \& Exercise, 31(7), 987-997. https://doi.org/ 10.1097/00005768-199907000-00011

Puterman, E., Weiss, J., Lin, J., Schilf, S., Slusher, A. L., Johansen, K. L., \& Epel, E. S. (2018). Aerobic exercise lengthens telomeres and reduces stress in family caregivers: A randomized controlled trial - Curt Richter Award Paper 2018. Psychoneuroendocrinology, 98, 245-252. https://doi.org/10. 1016/j.psyneuen.2018.08.002

Radak, Z., Apor, P., Pucsok, J., Berkes, I., Ogonovszky, H., Pavlik, G., Nakamoto, H., \& Goto, S. (2003). Marathon running alters the DNA base excision repair in human skeletal muscle. Life Sciences, 72(14), 16271633. https://doi.org/10.1016/S0024-3205(02)02476-1

Rae, D. E., Vignaud, A., Butler-Browne, G. S., Thornell, L.-E., Sinclair-Smith, C., Derman, E. W., Lambert, M. I., \& Collins, M. (2010). Skeletal muscle telomere length in healthy, experienced, endurance runners. European Journal of Applied Physiology, 109(2), 323-330. https://doi.org/10.1007/ s00421-010-1353-6

Ristow, M., \& Zarse, K. (2010). How increased oxidative stress promotes longevity and metabolic health: The concept of mitochondrial hormesis (mitohormesis). Experimental Gerontology, 45(6), 410-418. https://doi. org/10.1016/j.exger.2010.03.014

Saretzki, G., \& Von Zglinicki, T. (2002). Replicative aging, telomeres, and oxidative stress. Annals of the New York Academy of Sciences, 959(1), 2429. https://doi.org/10.1111/j.1749-6632.2002.tb02079.x

Shammas, M. A. (2011). Telomeres, lifestyle, cancer, and aging. Current Opinion in Clinical Nutrition and Metabolic Care, 14(1), 28-34. https:// doi.org/10.1097/MCO.0b013e32834121b1

Shin, Y. A., Lee, J. H., Song, W., \& Jun, T. W. (2008). Exercise training improves the antioxidant enzyme activity with no changes of telomere length. Mechanisms of Ageing and Development, 129(5), 254-260. https://doi. org/10.1016/j.mad.2008.01.001

Silva, L. C., de Araujo, A. L., Fernandes, J. R., Matias, M. D. S. T., Silva, P. R., Duarte, A. J. S., Garcez Leme, L. E., \& Benard, G. (2016). Moderate and intense exercise lifestyles attenuate the effects of aging on telomere length and the survival and composition of T cell subpopulations. Age, 38(1), 24. https://doi.org/10.1007/s11357-016-9879-0

Sirabella, D., De Angelis, L., \& Berghella, L. (2013). Sources for skeletal muscle repair: From satellite cells to reprogramming. Journal of Cachexia, Sarcopenia and Muscle, 4(2), 125-136. https://doi.org/10. 1007/s13539-012-0098-y

Soares-Miranda, L., Imamura, F., Siscovick, D., Jenny, N. S., Fitzpatrick, A. L., \& Mozaffarian, M. D. (2015). Physical activity, physical fitness, and leukocyte telomere length. Medicine \& Science in Sports \& Exercise, 47(12), 2525-2534. https://doi.org/10.1249/MSS.0000000000000720 
Sousa, C. V., Aguiar, S. S., Santos, P. A., Barbosa, L. P., Knechtle, B., Nikolaidis, P. T., Deus, L. A., Sales, M. M., Rosa, E. C. C. C., Rosa, T. S., Lewis, J. E., Andrade, R. V., \& Simões, H. G. (2019). Telomere length and redox balance in master endurance runners: The role of nitric oxide. Experimental Gerontology, 117, 113-118. https://doi.org/10.1016/j. exger.2018.11.018

Werner, C., Furster, T., Widmann, T., Pöss, J., Roggia, C., Hanhoun, M., Scharhag, J., Büchner, N., Meyer, T., Kindermann, W., Haendeler, J., Böhm, M., \& Laufs, U. (2009). Physical exercise prevents cellular senescence in circulating leukocytes and in the vessel wall. Circulation, 120 (24), 2438-2447. https://doi.org/10.1161/CIRCULATIONAHA.109.861005

Werner, C. M., Hecksteden, A., Morsch, A., Zundler, J., Wegmann, M., Kratzsch, J., Thiery, J., Hohl, M., Bittenbring, J. T., Neumann, F., Böhm, M., Meyer, T., \& Laufs, U. (2019). Differential effects of endurance, inter$\mathrm{val}$, and resistance training on telomerase activity and telomere length in a randomized, controlled study. European Heart Journal, 40(1), 34-46. https://doi.org/10.1093/eurheartj/ehy585
Williams, D. M., Buxton, J. L., Kantomaa, M. T., Tammelin, T. H., Blakemore, A I. F., \& Järvelin, M. R. (2017). Associations of leukocyte telomere length with aerobic and muscular fitness in Young adults. American Journal of Epidemiology, 185(7), 529-537. https://doi.org/10.1093/aje/kww123

Wolkowitz, O. M., Mellon, S. H., Epel, E. S., Lin, J., Dhabhar, F. S., Su, Y., Reus, V. I., Rosser, R., Burke, H. M., Kupferman, E., Compagnone, M., Nelson, J. C., \& Blackburn, E. H. (2011). Leukocyte telomere length in major depression: Correlations with chronicity, inflammation and oxidative stresspreliminary findings. PloS One, 6(3), e17837. https://doi.org/10.1371/jour nal.pone.0017837

Zhang, L., Hu, X. Z., Li, X., Li, H., Smerin, S., Russell, D., \& Ursano, R. J. (2014). Telomere length - a cellular aging marker for depression and posttraumatic stress disorder. Medical Hypotheses, 83(2), 182-185. https:// doi.org/10.1016/j.mehy.2014.04.033

Zhao, J., Miao, K., Wang, H., Ding, H., \& Wang D. W. (2013). Association between telomere length and type 2 diabetes mellitus: A meta-analysis. PloS One, 8(11), e79993. https://doi.org/10.1371/journal.pone.0079993 